\title{
Penerapan Metode Belajar Inkuiri untuk Meningkatkan Hasil Belajar Pkn Materi Pokok Nilai-Nilai Pancasila dalam Kerangka Praktik Penyelenggaraan Pemerintahan Negara
}

\author{
Enderina Wairata ${ }^{1 *}$ \\ ${ }^{1}$ SMKS Bhakti Persada Jailolo, Indonesia
}

\section{ART ICLE INFO}

Article history:

Received May 16, 2021

Revised May 25, 2021

Accepted June 06, 2021

Available online August 25, 2021

Kata Kunci:

Inkuiri, Hasil Belajar PKn

Keywords:

Inquiry, Civics Learning Outcomes

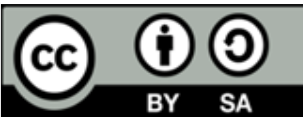

This is an open access article under the CC BY-SA license.

Copyright (ㅇ 2021 by Author. Published by Universitas Pendidikan Ganesha.

\begin{abstract}
A B S T R A K
Kurangnya penggunaan model pembelajaran yang sesuai pada mata pelajaran $\mathrm{PKn}$ berakibat pada belum tercapainya nilai ketuntasan minimal siswa. Sehingga tujuan utama dalam penelitian ini yaitu: untuk mengetahui peningkatan hasil belajar siswa pada mata pelajaran PKN bagi siswa kelas $\mathrm{X}$. Penelitian ini adalah penelitian tindakan kelas. Subjek yang terlibat dalam penelitian ini adalah 18 orang siswa. Indikator keberhasilan penelitian ini adalah selama proses pembelajaran dan dilakukannya refleksi ternyata adanya peningkatan hasil belajar mata pelajaran PKN bagi siswa kelas $X$. Metode pengumpulan data yang digunakan pada penelitian ini yaitu: observasi, tes dokumentasi dan wawancara. Hasil penelitian menunjukkan terdapat peningkatan nilai rata rata siswa dari tahap prasiklus sampai pada tahap siklus II. Pada tahap prasiklus persentase ketuntasan siswa hanya sebesar 33\%, kemudian meningkat pada siklus I menjadi $72 \%$, dan meningkatkan kembali pada siklus II hingga mencapai $100 \%$. Hasil peningkatan persentases ketuntasan ini menunjukkan bahwa penerapan metode pembelajaran inkuiri pada mata pelajaran PKn dengan materi pokok Nilai-nilai Pancasila dalam Kerangka Praktik Penyelenggaraan Pemerintahan Negara dapat meningkatkan hasil belajar siswa kelas X.
\end{abstract}

\begin{abstract}
A B S T RA C T
The lack of use of appropriate learning models in Civics subjects has resulted in not achieving the minimum mastery scores for students. So that the main objectives in this study are: to determine the improvement of student learning outcomes in PKN subjects for class $X$ students. This research is classroom action research. Subjects involved in this study were 18 students. The indicator of the success of this research is that during the learning process and reflection, it turns out that there is an increase in learning outcomes for PKN subjects for class $X$ students. The data collection methods used in this study are: observation, documentation test and interviews. The results showed that there was an increase in the average score of students from the pre-cycle stage to the second cycle stage. At the pre-cycle stage the percentage of students' completeness was only $33 \%$, then increased in the first cycle to $72 \%$, and increased again in the second cycle to reach $100 \%$. The results of this increase in the percentage of completeness indicate that the application of the inquiry learning method in Civics subjects with the main material Pancasila Values in the Framework of State Government Administration Practices can improve the learning outcomes of class $X$ students.
\end{abstract}

\section{PENDAHULUAN}

Pendidikan nasional berdasarkan Pancasila bertujuan untuk meningkatkan kualitas manusia Indonesia, yaitu manusia yang beriman dan bertaqwa terhadap Tuhan Yang Maha Esa, berbudi pekerti luhur, berkepribadian, berdisiplin, bekerja keras, tangguh, bertanggungjawab, mandiri, cerdas dan terampil serta sehat jasmani dan rohani (Lesmana, 2018; Winataputra, 2016). Pendidikan nasional juga harus mampu menumbuhkan dan memperdalam rasa cinta pada tanah air, mempertebal semangat kebangsaan dan rasa kesetiakawanan sosial. Dalam dunia pendidikan kita sering mendengar ungkapan yang cukup sederhana bahwa mendidik anak pada masa kini berarti menyiapkan orang dewasa di masa mendatang. Hal ini mengandung makna bahwa pendidik harus bisa menyiapkan anak didik menjadi orang 
dewasa yang mandiri, mampu menggunakan dan mengembangkan sendiri kemampuan (pengetahuan dan keterampilan) yang telah dimilikinya, dan mempunyai sikap yang sesuai dengan norma-norma yang berlaku di masyarakat (Iryanti, 2019; Komariyah, 2021; Yuristia, 2018).

Sejalan dengan hal tersebut maka perlu dikembangkan iklim belajar mengajar yang dapat menumbuhkan rasa percaya diri serta sikap dan perilaku yang inovatif dan kreatif. Dengan demikian pendidikan nasional akan mampu mewujudkan manusia manusia pembangunan yang dapat membangun dirinya sendiri serta bersama-sama bertanggung jawab atas utuhnya Negara Kesatuan Republik Indonesia. Salah satu mata pelajaran yang mampu mengembangkan rasa tanggung jawab siswa terhadap keutuhan NKRI adalah mata pelajaran pendidikan kewarganegaraan (PKn) (Nasution, 2019; Nurnazhiifa \& Dewi, 2021). Pendidikan Pancasila dan Kewarganegaraan adalah pendidikan tentang nilai-nilai yang sasarannya bukan semata-mata pengalihan pengetahuan melainkan lebih ditekankan pada pembentukan sikap (Komariyah, 2021; Nirmayani, 2020; Praptiningsih, 2020). Dengan demikian mata pelajaran PKn meliputi ranah kognitif, afektif dan psikomotor, yang lebih menitikberatkan pada ranah afektif. dengan menekankan materi Nilai-nilai Pancasila Dalam kerangka praktik penyelenggaraan Pemerintahan Negara (Ananda \& Hudaidah, 2021; Santika, 2020).

Pendidikan Kewarganegaraan akan menjadi dasar dalam pembentukan kepribadian siswa dimana pada hakikatnya dipengaruhi oleh ranah kognitif, apektif dan psikomotor (Abdulatif \& Dewi, 2021). Ketiga ranah tersebut menyatu dan sulit dipisahkan satu dengan yang lainnya, sehingga membentuk kepribadian unik setiap manusia. Dalam menyajikan pelajaran, guru harus berupaya mengembangkan ketiga ranah tersebut agar berkembang sesuai dengan yang diharapkan. Dalam pelaksanaan pembelajaran terdapat perbedaan strategi hal ini tergantung dari ranah mana yang mendapat penekanan, sementara dalam pembelajaran PKn, hasil akhir yang menjadi tujuan adalah pengembangan ranah apektif yang sesuai dengan nilai dan norma yang berlaku dan berkembang dalam tatanan kehidupan manusia Indonesia (Simangunsong, 2018).

Namun dalam proses pembelajaran PKn, guru belum semuanya melaksanakan pendekatan siswa aktif, dan peranan guru sebagai fasilitator belum diterapkan dengan maksimal, masih banyak guru yang dominan menggunakan metode ceramah dan tanya jawab (Luistari \& Adisel, 2021). Dalam penyampaian materi pelajaran guru masih menggunakan buku-buku sumber dan buku pelengkap sebagai sumber belajar, dan dalam penyampaian bahan ajar kepada siswa belum digunakan media belajar yang lain, sehingga pembelajaran berlangsung satu arah (Teacher Centred) (Sulfemi \& Yuliana, 2019). Hal ini berdampak terhadap hasil belajar yang dicapai siswa belum mencapai nilai rata-rata KKM yang ditentukan sekolah adalah 75. Rendahnya hasil belajar PKn siswa dibuktikan dengan hasil observasi yang dilakuakan di SMKS Bhakti Persada pada tahap awal dari Penelitian. Hasil observasi menunjukkan bahwa hasil belajar siswa masih rendah yaitu dengan nilai rata-rata 71 dan ketuntasan belajar mencapai 33\%. Untuk mengatasi permasalahan yang muncul pada mata pelajaran PKn dan meningkatkan hasil belajar PKn maka dibutukan suatu inovasi pembelajaran dengan mengembangkan berbagai model pembelajaran yang relevan. Salah satu model pembelajaran yang cocok digunakan untuk meningkatkan hasil belajar PKn siswa yakni model pembelajaran inquiri.

Model pembelajaran inquiri merupakan suatu rangkaian kegiatan belajar yang melibatkan secara maksimal seluruh kemampuan siswa untuk mencari dan menyelidiki secara sistematis, kritis, logis, dan analitis (Uliyandari \& Lubis, 2020; Zani et al., 2018). Sehingga mereka dapat merumuskan sendiri penemuannya dengan penuh percaya diri. Dengan kata lain, inkuiri adalah suatu proses untuk memperoleh dan mendapatkan informasi dengan melakukan observasi atau eksperimen untuk mencari jawaban atau memecahkan masalah terhadap pertanyaan atau rumusan masalah dengan menggunakan kemampuan berpikir kritis dan logis (Jundu et al., 2020; Sitorus et al., 2019). Kegiatan pembelajaran dengan menggunakan model inquiri biasanya dilaksanakan dengan kegiatan tanya jawab antara guru dan siswa (Widani et al., 2019). Hal ini dilakukan untuk mengupayakan agar siswa mampu menemukan sendiri konsep yang dipelajari, sehingga siswa akan lebih memahami ilmu, dan ilmu tersebut akan bertahan lama

Penerapan model inkuiri akan mampu meningkatkan ingatan siswa dimana dengan inkuiri guru dapat mempersiapkan peserta didik pada situasi untuk melakukan eksperimen sendiri secara luas agar melihat apa yang terjadi, ingin melakukan sesuatu, mengajukan pertanyaan-pertanyaan dan mencari jawabannya sendiri, serta menghubungkan penemuan yang lain, membandingkan apa yang ditemukannya dengan yang ditemukan peserta didik lainnya.Sehingga secara tidak langsung akan berdampak pada peningkatan hasil belajar siswa. Pernyataan ini sejalan dengan penelitian (Sulianti \& Murdiono, 2017) yang menunjukkan hasil bahwa penggunaan model inkuiri pada pembelajaran PKn dapat memberikan pengaruh yang signifikan terhadap peningkatan hasil belajar PKn siswa. Penelitian relevan kedua yakni penelitian oleh (Mustaricha, 2019) yang juga menunjukkan hasil bahwa model pembelajaran inkuiri dapat meningkatkan kemampuan berpikir kritis siswa. Dan penelitian relevan yang ketiga yakni penelitian yang 
dilakukan oleh (Naiborhu, 2018) dengan hasil penelitian yang menunjukkan bahwa penggunaan model inkuiri berbasis media pembelajaran secara signifikan mampu meningkatkan hasil belajar PKn. Hasil pada penelitian sebelumnya menunjukkan bahwa penggunaan model inkuiri dalam pembelajaran PKn secara signifikan mampu meningkatkan hasil belajar serta kemampuan berpikir kritis siswa. Sehingga berdasarkan hal tersebut adapun tujuan dari penelitian ini yakni untuk mengetahui peningkatan hasil belajar siswa pada mata pelajaran PKN bagi siswa kelas X Semester Ganjil SMKS Bhakti Persada tahun pelajar 2017/2018.

\section{METODE}

Penelitian ini menggunakan jenis penelitian tindakan kelas yang merupakan penelitian yang bersifat aplikasi (terapan), terbatas, segera, dan hasilnya untuk memperbaiki dan menyempurnakan proses atau program (program pembelajaran) yang sedang berlangsung (Agung, 2014). Penelitian tindak kelas ditandai dengan adanya perbaikan terus menerus sehingga tercapai sasaran dari penelitian tersebut. Penelitian tindakan kelas terbagi menjadi 2 siklus. Pada masing-masing siklus terdapat 4 tahapan yang terdiri dari planing, action, observation/evaluation, dan reflection. Gamabaran mengenai tahapan siklus dapat dilihat pada gambar 1 .

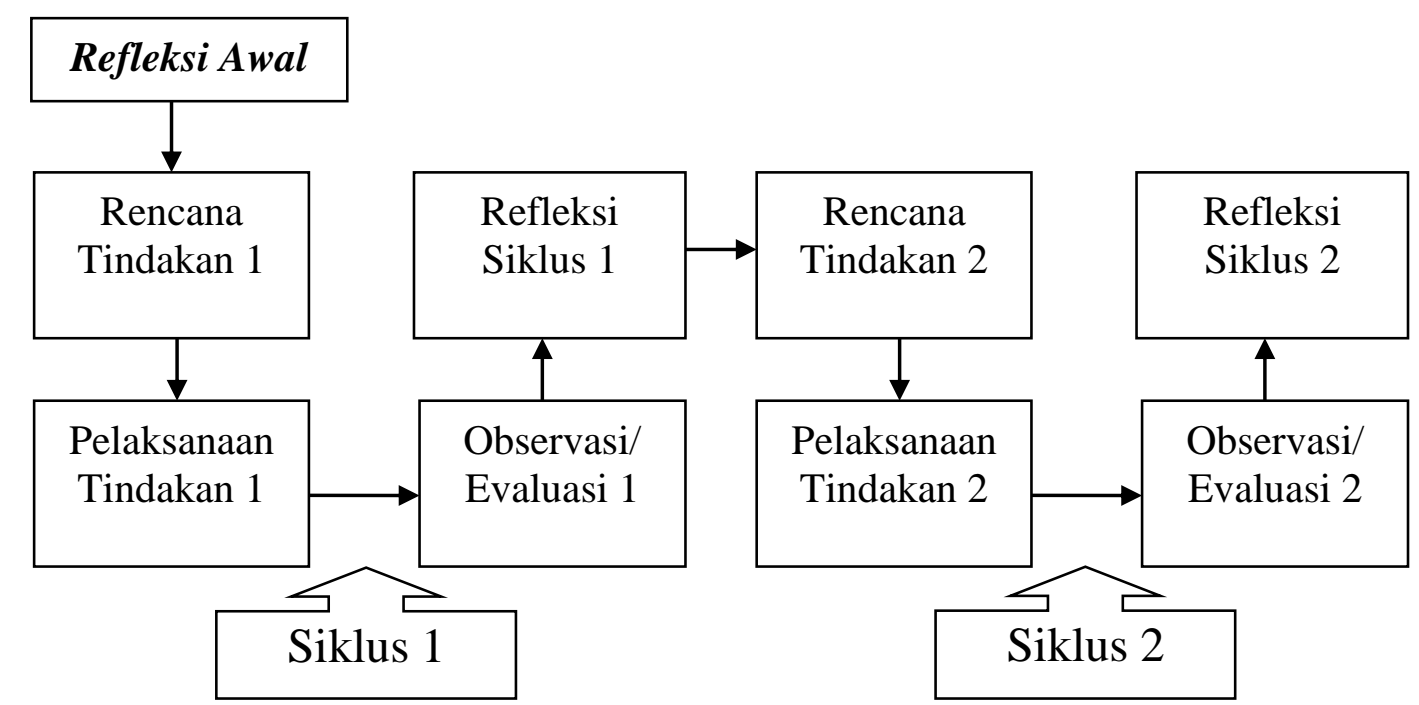

Gambar 1. Tahapan pelaksanaan penelitian

Penelitian ini dilakukan di Kelas X Semester Ganjil SMKS Bhakti Persada yang beralamatkan di Kecamatan Jailolo Kab. Halmahera Barat, Propinsi Maluku Utara. Waktu Penelitian mulai dari Perencanaan sampai dengan penulisan laporan hasil penelitian tersebut mulai dari bulan Juli s.d September tahun 2017, pada semester ganjil tahun pelajaran 2017/2018, sedangkan penulisan laporan hasil PTK dilaksanakan sampai dengan bulan Desember. Subjek yang terlibat dalam penelitian ini adalah siswa kelas X Semester Ganjil sebayak 18, semua laki-laki orang siswa. Pelaksnaan Penelitian Tindakan Kelas ini di kosentrasikan pada kemampuan siswa dalam memaknai konsep materi pelajaran PKn tentang nilai-nilai Pancasila Dalam Kerangka Praktik Penyelenggaraan Pemerintahan Negara. Metode pengumpulan data yang digunakan pada penelitian ini yaitu: observasi, tes dokumentasi dan wawancara. Analisis data yang digunakan pada penelitian ini adalah metode analisis deskriptif kuantitatif.

\section{HASIL DAN PEMBAHASAN}

Hasil belajar siswa pada siklus I menunjukkan bahwa terjadi terjadi peningkatan sebanyak 39\% dari tahap prasiklus. Namun demikian pada siklus I masih terdapat siswa yang belum mencapai ketuntasan belajar sebanyak 5 orang siswa. Pada siklus I nilai rata-rata yang dicapai siswa telah terjadi peningkatan diatas KKM yaitu 78. Berdasarkan Hasl yang diperoleh pada siklus I, maka diperlukan refleksi dengan memberikan bimbingan kepada siswa yang belum mencapai ketuntasan belajara pada siklus I. Refleksi dilakukan untuk mencapai peningkatan hasil yang lebih baik serta mengoptimalkan metode inkuiri dengan memberikan motivasi kepada siswa agar siswa dapat berdiskusi secara lebih baik 
pada siklus II. Hasil pada siklus II menunjukkan adanya peningkatan terhadap hasil belajar siswa, dimana jumlah rata-rata ketuntasan siswa mencapai 100\%. Secara lebih rinci peningkatan hasil belajar siswa pada tahap prasiklus, siklus I dan siklus II dapat dilihat pada Tabel 1.

Tabel 1. Hasil pembelajaran pada tahap prasiklus, siklus I, dan siklus II

\begin{tabular}{lccc}
\hline \multicolumn{1}{c}{ Uraian } & Prasiklus & Siklus I & Siklus II \\
\hline Jumlah siswa yang tuntas & 6 & 13 & 18 \\
Rata-rata & 71 & 78 & 83 \\
Persentase ketuntasan & $33 \%$ & $72 \%$ & $100 \%$ \\
\hline
\end{tabular}

Berdasarkan tabel 1. dapat diketahui bahwa terdapat peningkatan hasil belajar siswa dari tahap prasiklus, siklus I, dan siklus II. Hasil yang diperoleh dalam penelitian ini sejalan dengan hasil penelitian (Sulianti \& Murdiono, 2017) yang menunjukkan hasil bahwa penggunaan model inkuiri pada pembelajaran PKn dapat memberikan pengaruh yang signifikan terhadap peningkatan hasil belajar PKn siswa. Penelitian relevan kedua yakni penelitian oleh (Mustaricha, 2019) yang juga menunjukkan hasil bahwa model pembelajaran inkuiri dapat meningkatkan kemampuan berpikir kritis siswa. Dan penelitian relevan yang ketiga yakni penelitian yang dilakukan oleh (Naiborhu, 2018) dengan hasil penelitian yang menunjukkan bahwa penggunaan model inkuiri berbasis media pembelajaran secara signifikan mampu meningkatkan hasil belajar PKn.

Peningkatan terhadap hasil belajar siswa pada setiap siklusnya tidak terlepas dari penggunaan model pembelajaran inkuiri. Model pembelajaran inkuiri memungkinkan peserta didik untuk memaksimalkan proses pembelajarannya dengan merekonstruksi pengetahuannya sendiri (Iswatun et al., 2017). Hal ini dikarenakan model pembelajaran inkuiri merupakan model pembelajaran yang berbasis penyelidikan dimana peserta didik mencari sendiri jawaban dari permasalahan yang dihadapi (Kusdiastuti et al., 2016). Melalui pembelajaran inkuiri peserta didik mampu mendapatkan pengalaman belajar yang konkret dan bermakna. Pelaksanaan pembelajaran inkuiri dilakukan dengan memberikan pertanyaan kepada siswa guna merangsang proses berpikir siswa. Melalui pertaanyaan yang diberikan siswa dituntut untuk menjawab pertanyaan yang ada serta memcahkan masalah yang disajikan. Berdasarkan prosedur pembelajaran tersebut siswa akan dapat lebih aktif dan kreatif dalam belajar sehingga dapat meningkatkan hasil belajarnya.

\section{SIMPULAN}

Berdasarkan penelitian yang telah dilakukan dapat disimpulkan penerapan metode pembelajaran inkuiri pada mata pelajaran PKn dengan materi pokok Nilai-nilai Pancasila dalam Kerangka Praktik Penyelenggaraan Pemerintahan Negara dapat meningkatkan hasil belajar siswa kelas X Semester Ganjil SMKS Bhakti Persada Tahun pelajaran 2017/2018. Hasil ini tercermin pada rerata hasil belajar siklus I adalah 78, sedangkan pada siklus II meningkat menjadi 83. Setelah disimpulkan dari hasil penelitian ini, maka dapat disarankan agar penerapan metoda belajar inkuiri yang telah terbukti keberhasilannya dapat diteruskan pelaksanaannya dalam pembelajaran KPKn di SMKS Bhakti Persada Jailolo Kabupaten Halmehera Barat demikian juga kepa guru mata pelajaran lainnya, karena menurut Peneliti Pembelajaran dengan menggunakan metoda inkuiri dapat membantu siswa untuk meningkatkan kemandiriannya serta meningkatkan nhasil belajar pada tingkat yang lebih baik.

\section{DAFTAR RUJUKAN}

Abdulatif, S., \& Dewi, D. A. (2021). Peranan pendidikan kewarganegaraan dalam membina sikap toleransi antar siswa. Jurnal Pendidikan Dan Pengajaran Guru Sekolah Dasar (JPPGuseda), 4(2), 103-109. https: //doi.org/10.33751/ jppguseda.v4i2.3610.

Agung, G. (2014). Metodelogi Penelitian Pendidikan. Aditya Media Publishing.

Ananda, A. P., \& Hudaidah. (2021). Perkembangan Kurikulum Pendidikan Indonesia Dari Masa Ke Masa. Jurnal Pendidikan Sejarah Dan Kajian Sejarah, https://doi.org/https://doi.org/10.31540/sindang.v3i2.1192.

Iryanti, E. (2019). Upaya Meningkatkan Hasil Belajar PKn Melalui Model Pembelajaran Kooperatif Tipe Round Club Peserta Didik Kelas IV A SD Negeri 64/IV Kota Jambi. Jurnal Ilmiah Universitas Batanghari Jambi, 19(2), 264-273. https://doi.org/10.33087/jiubj.v19i2.644.

Iswatun, I., Mosik, M., \& Subali, B. (2017). Penerapan Model Pembelajaran Inkuiri Terbimbing untuk Meningkatkan KPS dan Hasil Belajar Siswa SMP Kelas VIII. Jurnal Inovasi Pendidikan IPA, 3(2), 150-160. https://doi.org/https://doi.org/10.21831/jipi.v3i2.14871. 
Jundu, R., Tuwa, P. H., \& Seliman, R. (2020). Hasil Belajar IPA Siswa SD di Daerah Tertinggal dengan Penerapan Model Pembelajaran Inkuiri Terbimbing. Jurnal Pendidikan Dan Kebudayaan, 10(2), 103-111. https://doi.org/https://doi.org/10.24246/j.js.2020.v10.i2.p103-111.

Komariyah. (2021). Pengaruh Metode Inkuiri Terhadap Pembelajaran PKn Pada Siswa Kelas V SD. Jurnal Inovasi Dan Riset Akademik, 2(1), 58-64. https://doi.org/https://doi.org/10.47387/jira.v2i1.73.

Kusdiastuti, M., Harjono, A., \& Sahidu, H. (2016). Pengaruh Model Pembelajaran Inkuiri Berbantuan Laboratorium Virtual Terhadap Penguasaan Konsep Fisika Peserta Didik. Jurnal Pendidikan Fisika Dan Teknologi, 2(3), 116-122. https://doi.org/http://dx.doi.org/10.29303/jpft.v2i3.298.

Lesmana, D. (2018). Kandungan Nilai Dalam Tujuan Pendidikan Nasional (Core Ethical Values). Jurnal Komuikasi, 17(1). https://doi.org/10.15408/kordinat. v17i1.8103.

Luistari, D., \& Adisel. (2021). Peran guru pendidikan kewarganegaraan dalam membentuk karakter peserta didik agar menciptakan siswa yang berkualitas. Journal Scientific of Mandalika, 2(8), 429437.

Mustaricha, M. (2019). Efektivitas Model Pembelajaran Inkuiri Dalam Meningkatkan Kemampuan Berpikir Kritis Siswa Pada Matapelajaran Pendidikan Pancasila Dan Kewarganegaraan. Jurnal Ilmiah Pendidikan Pancasila Dan Kewarganegaraan, 4(2), 368-373. http://dx.doi.org/ 10.17977/um019v4i2p375-380.

Naiborhu, M. (2018). Pengaruh Yang Signifikan Model Pembelajaran Inkuiri Berbasis Media Video Terhadap Hasil Belajar Pkn Di Kelas X Smk Farmasi Ypfsu Medan T.A. 2017/2018. Jurnal Civic Education $1(1)$

$24-30$. http://jurnal.darmaagung.ac.id/index.php/civiceducation/article/view/152/172.

Nasution, N. (2019). Meningkatkan Minat Belajar Siswa Melalui Model Pembelajaran Group Investigation Pada Mata Hasil Belajar Siswa Kelas V Semester Ganjil Di SD Negeri 97 Pekanbarutahun AjaraN 2015/2016. Jurnal Pendidikan Tambusai, 3(1), 526-535. https://www.jptam.org/index.php/ jptam/article/view/242/228.

Nirmayani, L. H. (2020). Peningkatan Kualitas Pembelajaran PKn di Sekolah Dasar Melalui Model Pengajaran Bermain Peran. Jurnal Pendidikan Dasar, 1(2), 207-215. http://stahnmpukuturan.ac.id/jurnal/index.php/edukasi/article /view/925.

Nurnazhiifa, K., \& Dewi, D. A. (2021). PPKN Sebagai Tonggak Rasa Patriotisme Dan Nasionalisme Berkaitan Dengan Identitas Nasional. Indonesian Journal of Islamic Studies, 2(2), 67-79. https://doi.org/https://www.jptam.org/index .php/jptam/article/view/242/228.

Praptiningsih. (2020). Peran Guru Mata Pelajaran Pendidikan Kewarganegaraan Dalam Pengembangan Nilai Moral Pancasila Siswa SMK PGRI III Salatiga. Jurnalwawasan Pengembangan Pendidikan, 8(2). http://ejournal.undaris .ac.id/index.php/waspada/article/view/170/127.

Santika, I. W. E. (2020). Pendidikan Karakter pada Pembelajaran Daring. Indonesian Values and Character Education Journal, 3(1), 8-19.

Simangunsong, M. (2018). Upaya Meningkatkan Hasil Belajar Siswa Pada Mata Pelajaran Pendidikan Kewarganegaraan (PKN) Melalui Metode Inquiri Di Kelas III SD Negeri 168060 Kota Tebing $\begin{array}{lllll}\text { Tinggi. School } & \text { Education } & \text { Journal, } & \text { 414), }\end{array}$ https://doi.org/https://doi.org/10.24114/sejpgsd.v8i4.11639.

Sitorus, R. P. S., Situmorang, R., \& Asiah, H. I. (2019). Pengaruh Model Pembelajaran Inkuiri Terbimbing Terhadap Keterampilan Proses Sains Siswa Pada Materi Pokok Momentum Dan Impuls Di KelaS X Semester II SMA Negeri 1 Tanjung Morawa T.P 2017/2018. Jurnal Inovasi Pembelajaran Fisika, 7(4), 42-49. https://doi.org/https://doi.org/10.24114/inpafi. v7i4.17076.

Sulfemi, W. B., \& Yuliana, D. (2019). Penerapan model pembelajaran discovery learning meningkatkan motivasi dan hasil belajar pendidikan kewarganegaraan. Jurnal Rontal Keilmuan PKn, 5(1), 17-30. https://doi.org/https://doi.org/10.29100/jr.v5i1.1021.

Sulianti, A., \& Murdiono, M. (2017). Pengaruh Model Pembelajaran Inkuiri Terhadap Keterampilan Berpikir Kritis Dan Hasil Belajar Peserta Didik. Jurnal Pendidikan IPS, 4(2), 165-175. https://doi.org/https://doi.org/ 10.21831/hsjpi.v4i2.10020.

Uliyandari, M., \& Lubis, E. E. (2020). Penerapan Model Pembelajaran Inkuiri Dan Media Alat Peraga (Gunung Berapi) Pada Mata Pelajaran IPA SDN 013 Bengkulu Utara. PENDIPA Journal of Science Education, 4(2), 74-78. https://doi.org/10.33369/pendipa.4.2.74-78.

Widani, N. K. T., Sudana, D. N., \& Agustiana, I. G. A. T. (2019). Pengaruh Model Pembelajaran Inkuiri Terbimbing Terhadap Hasil Belajar Ipa Dan Sikap Ilmiah Pada Siswa Kelas V Sd Gugus I Kecamatan Nusa Penida. Journal of Education Technology, 3(1), 15. https://doi.org/10 .23887/jet.v3i1.17959.

Winataputra, U. S. (2016). Posisi Akademik Pendidikan Kewarganegaraan (PKn) Dan Muatan/Mata Pelajaran Pendidikan Pancasila Dan Kewarganegaraan (PPKn) Dalam Konteks Sistem Pendidikan 
Nasional. Jurnal Moral Kemasyarakatan, 1(1), 15-36. https://doi.org/https://doi.org/10.21067 /jmk.v1i1.1184.

Yuristia, A. (2018). Pendidikan Sebagai Transformasi Kebudayaan. Jurnal Ilmu Sosial Dan Budaya, 2(1). http://jurnal.uinsu.ac.id/index.php/ijtimaiyah/ article/view/5714.

Zani, R., Safitri, R., \& Adlim. (2018). Penerapan Model Pembelajaran Inkuiri Terbimbing pada Materi Fluida Statis Untuk Meningkatkan Hasil Belajar dan Keterampilan Proses Sains Siswa. Jurnal IPA Dan Pembelajaran IPA, 2(2), 56-63. https://doi.org/https://doi.org/10.24815/jipi.v2i2.11622. 